\title{
Undetectable = Untransmissible: Unpacking HIV Risk and Transmission Concerns for Women Living With HIV
}

\section{Brent Allan $^{1}$, Jessica Whitbread ${ }^{2}$ and Mary Ann Torres ${ }^{3 *}$}

${ }^{1}$ Senior Advisor, International Council of AIDS Service Organizations, Canada

${ }^{2}$ Consultant and woman living with HIV, Canada

${ }^{3}$ Executive Director, International Council of AIDS Service Organizations, Canada

*Corresponding author: Mary Ann Torres, Executive Director, International Council of AIDS Service Organizations, Canada

Keywords: HIV; Community; Women; Vertical transmission

\section{Short Communication}

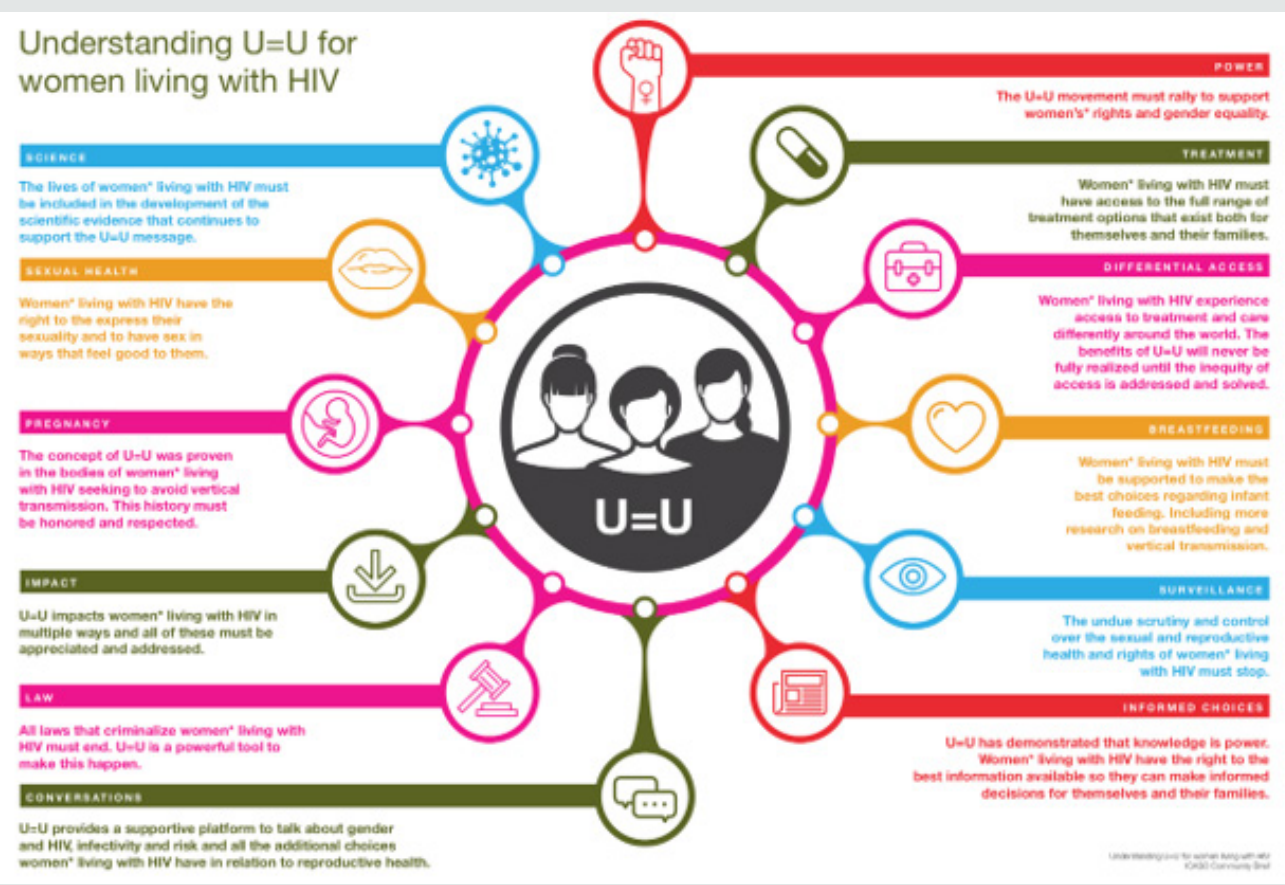

Figure 1

The notion that Undetectable $=$ Untransmissible $(\mathrm{U}=\mathrm{U})$ is revolutionizing the way people living with HIV are seen and treated around the world. No longer the harbingers of disease and death, those living with HIV who take HIV anti-retroviral therapy (ART) daily as prescribed and achieve and maintain an undetectable viral load ( $<50$ copies $/ \mathrm{ml}$ ) have effectively no risk of sexually transmitting the virus to an HIV-negative partner [1]. The global $\mathrm{U}=\mathrm{U}$ campaign has been credited with beginning to change public perception of HIV transmissibility [2]. However, sexual transmission of HIV is only one way in which HIV is transmitted and it is women living 
with HIV who have to shoulder the additional burden of the risk of possibly transmitting HIV to their child either pre or post nattily. And even though the basis of the rationale behind $\mathrm{U}=\mathrm{U}$ was proven almost two decades ago by proving that a woman prescribed ART and is virally suppressed prior to contraception, and remains undetectable throughout their pregnancy, there is virtually no vertical transmission of HIV from a mother to her infant [3] (Figure 1).

To explore some of the questions and concerns of women living with HIV regarding the broad application of $\mathrm{U}=\mathrm{U}$ to their lives, ICASO commissioned a Community Brief on $\mathrm{U}=\mathrm{U}$ for women living with HIV. Launched in September 2018 at the National AIDS Conference in Australia, this brief was written by a team of women living with HIV and was guided by a global community advisory committee, also made up by women living with HIV. Together they collected stories from over 65 women living with HIV from around the world and held two community consultations at the International AIDS Conference in Amsterdam in July 2018 to refine and test the content and construction of the brief. In particular, this global brief focused upon capturing the voices of women living with HIV and contains quotes of over 20 women from every region in the world. Their voices illuminate the intensely personal experiences of pregnancy, motherhood and infant feeding as well as some of the nuances around sexuality, access, equity and gender which exist in the lives of women living with HIV. The widespread adoption of the $\mathrm{U}=\mathrm{U}$ discourse has provided an important opportunity to ensure that the sexual and reproductive rights of women living with HIV are recognized in the context of $U=U$ and importantly, the profile of the $\mathrm{U}=\mathrm{U}$ message has the potential to be a catalyst for the much-needed conversations about gender inequalities and violence, women's*1 self-determination, access to treatment, women's* involvement in research, body autonomy and informed choice as essential aspects in the lives of women* regardless of whether or not a woman* living with HIV is virally undetectable.

Perhaps the most contentious issue arising from the brief is the absence of quality research and evidence regarding the risk of HIV transmission via breastfeeding. There is an urgent need to recognize the social, emotional, practical and cultural challenges that women experience when it comes to the pressures, they are under to breastfeed or not with differing advice provided to women around the world often associated with access to clean water to provide infant formula in preference to breastfeeding. What the women expressed throughout the construction of the brief is a disconnect between medical evidence, breastfeeding guidelines, cultural practices and public health approaches to the risks and harms in relation to breastfeeding. What is most concerning is the fact that there is a fear on the part of women* living with HIV that they will not receive all the information on breastfeeding, nor will they receive appropriate social or medical support if they express their desire to breastfeed. This is both troubling and concerning. This prevents women* living with HIV from having the information they require to make their own informed decisions and choices that may affect the future health of their children and families.

This brief concludes with four actions that were ubiquitous across the communities of women* living with HIV that require urgent attention including;

I. The right of women* living with HIV to make informed choices about their sexual and reproductive rights, including the right to the birth control options of their choice as well as access to safe and legal abortion,

II. Better research into vertical transmission in the context of $\mathrm{U}=\mathrm{U}$,

III. Supporting and respecting women* living with HIV to make informed choices and the best decisions about infant feeding options for themselves and their children

IV. Increasing, improving and guaranteeing access to the range of HIV treatments that work best for women* living with HIV around the globe.

\section{Optional Quote}

"The U=U movement is transformative . . . so profound in its implication and impact but so simple in its concept. And women all women everywhere - too must benefit from this concept. More than ever before, we now have within our hands the opportunity to counter both perceived and experienced stigma and really embrace the fact that when individuals know their status, link to antiretroviral therapy and become virally suppressed then life can return to normal in the fullest sense."

\section{References}

1. (2017) HIV \& AIDS in the United States. CDC'S Division of HIV/AIDS Prevention.

2. Lenny Bernstein (2017) I don't feel like I'm a threat anymore. New HIV guidelines are changing lives. Health Science.

3. Mandelbrot L, Tubiana R, Le Chenadec J, Dollfus C, Faye A, et al. (2015) No perinatal HIV-1 transmission from women with effective antiretroviral therapy starting before conception. Clin Infect Dis 61(11): 1715-1725.

${ }^{1}$ This community brief acknowledges the diversity of women living with HIV, which includes transgender men, gender queer people and others identified female at birth. The writing team felt it was important to indicate this inclusivity in this brief by using an asterisk * where our diversity is included. 
This work is licensed under Creative Commons Attribution 4.0 License

To Submit Your Article Click Here: Submit Article

DOI: 10.32474/IGWHC.2019.03.000154
Interventions in Gynecology and Women's Healthcare

\section{IGWHC}

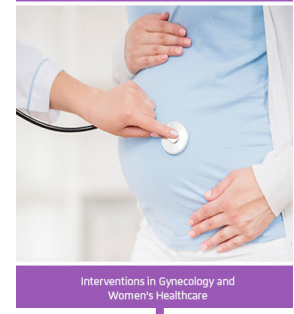

Assets of Publishing with us

- Global archiving of articles

- Immediate, unrestricted online access

- Rigorous Peer Review Process

- Authors Retain Copyrights

- Unique DOI for all articles 